\title{
The debate over digital technology and young people
}

\author{
Needs less shock and more substance
}

\author{
Vaughan Bell senior clinical lecturer ${ }^{1}$, Dorothy V M Bishop professor of developmental \\ neuropsychology ${ }^{2}$, Andrew K Przybylski research fellow ${ }^{3}$
}

${ }^{1}$ Division of Psychiatry, Faculty of Brain Sciences, University College London, London W1T 7NF, UK; ${ }^{2}$ Department of Experimental Psychology, University of Oxford, UK; ${ }^{3}$ Oxford Internet Institute, University of Oxford, UK

Through appearances, interviews, and a recent book ${ }^{1}$ Susan Greenfield, a senior research fellow at Lincoln College, Oxford, has promoted the idea that internet use and computer games can have harmful effects on the brain, emotions, and behaviour, and she draws a parallel between the effects of digital technology and climate change. Despite repeated calls for her to publish these claims in the peer reviewed scientific literature, where clinical researchers can check how well they are supported by evidence, this has not happened, and the claims have largely been aired in the media. As scientists working in mental health, developmental neuropsychology, and the psychological impact of digital technology, we are concerned that Greenfield's claims are not based on a fair scientific appraisal of the evidence, often confuse correlation for causation, give undue weight to anecdote and poor quality studies, and are misleading to parents and the public at large.

Greenfield claims that social networking sites could negatively affect social interaction, interpersonal empathy, and personal identity. ${ }^{1}$ However, the bulk of research does not support this characterisation. With regard to social interaction and empathy, adolescents' use of social networking sites has been found to enhance existing friendships and the quality of relationships, although some individuals benefit more than others. The general finding is that those who use social networks to avoid social difficulties have reduced wellbeing, while use of social networks to deal with social challenges improves outcomes. ${ }^{2}$ In terms of affecting personal identity, Facebook is the most widely used social network and the best studied, and evidence suggests that people generally portray their identity accurately. ${ }^{3}$

Notably, Greenfield has speculated that online interaction might be a "trigger" for autism or "autistic-like traits." This claim has no basis in scientific evidence and is entirely implausible in light of what we know of autism as a neurodevelopmental condition that can be first diagnosed in the preschool years. Her claims are misleading to the public, unhelpful to parents, and potentially stigmatising to people with autism.

Another of Greenfield's claims is that intense use of computer games could lead to impulsiveness, a shorter attention span, and aggression. ${ }^{1}$ Yet studies on video gaming give a much more nuanced conclusion. Evidence suggests that playing action video games produces a small improvement in neuropsychological performance, even when only the most stringently designed studies are considered. ${ }^{45}$ The effects of violent video games are still debated. Evidence exists for a small, transient increase in aggressive thoughts and behaviour, ${ }^{6}$ although there are concerns about the quality of the evidence underpinning this assertion. ${ }^{7}$ Nevertheless, generalisations about video games are unlikely to be helpful because multiplayer cooperative games are increasingly common, and evidence suggests these kinds of games might lead to an increase in socially beneficial thoughts and behaviour. ${ }^{8}$ This shows that content is important in terms of the potential emotional and behavioural influence of gaming. Another claim made by Greenfield is that reliance on search engines and surfing the internet could result in superficial mental processing at the expense of deep knowledge and understanding. ${ }^{1}$ There is indeed evidence that when people know they can access information through search engines they are less likely to remember the content. ${ }^{9}$ However, this effect applies to many situations and is not restricted to the use of technology; for instance, people who work in teams are less likely to remember facts when others hold the information, which allows for more efficient use of mental resources. This is a well studied and adaptive form of thinking called transactive memory. ${ }^{10}$

Taking the broader view from published research, current estimates are that internet use accounts for less than $1 \%$ of subjective estimates of wellbeing, ${ }^{11}$ and there is currently no evidence from neuroscience studies that typical internet use harms the adolescent brain. ${ }^{12}$

Nevertheless, valid concerns exist about digital technology, which are in danger of being overshadowed by the current debate. Rather than technology affecting children's capacities, the displacement of other activities seems to be an important source of negative effects. Low levels of physical activity associated with the passive use of digital technology have been linked to obesity and diabetes. ${ }^{13}$ For video games, the displacement of academic activities, rather than altered cognitive 
function, has been found to account for reduced school performance. ${ }^{14}$ Online safety is another important concern and needs to be understood in its widest sense: the risks of bullying, grooming, unintended or non-consensual sharing of sexual pictures, harm to reputation, fraud, and encountering distressing material. Consequently, safety needs to be tackled at individual, community, industry, and policy levels. ${ }^{15}$ Nevertheless, we need to recognise that use of the internet and digital technology has cognitive and social benefits and to balance these against any risks.

Accurate, informed information from sound scientific studies is essential to inform this process, and we think that it is unfortunate that Greenfield's media profile means her claims have an exaggerated impact on public debate given their limited evidence base. There is already much research into the many concerns about digital technology, and the public deserves to participate in the debate fully informed of all the evidence.

Competing interests: We have read and understood BMJ policy on declaration of interests and declare that we have no competing interests. Provenance and peer review: Commissioned; externally peer reviewed.

Greenfield S. Mind change: how digital technologies are leaving their mark on our brains. Rider, 2014.
2 Spies Shapiro LA, Margolin G. Growing up wired: social networking sites and adolescent psychosocial development. Clin Child Fam Psychol Rev 2014;17:1-18.

3 Wilson RE, Gosling SD, Graham LT. A review of Facebook research in the social sciences. Perspect Psychol Sci 2012;7:203-20.

4 Bisoglio J, Michaels TI, Mervis JE, Ashinoff BK. Cognitive enhancement through action video game training: great expectations require greater evidence. Front Psychol 2014;9:136.

5 Powers KL, Brooks PJ, Aldrich NJ, Palladino MA, Alfieri L. Effects of video-game play on information processing: a meta-analytic investigation. Psychon Bull Rev 2013;6:1055-79.

6 Anderson CA, Shibuya A, Ihori N, et al. Violent video game effects on aggression, empathy, and prosocial behavior in eastern and western countries: a meta-analytic review. Psychol Bull 2010;136:151-73.

7 Elson M, Ferguson CJ. Twenty-five years of research on violence in digital games and aggression: empirical evidence, perspectives, and a debate gone astray. Eur Psychol 2014;19:33-46.

8 Granic I, Lobel A, Engels RC. The benefits of playing video games. Am Psychologist 2014;69:66-78.

9 Sparrow B, Liu J, Wegner DM. Google effects on memory: cognitive consequences of having information at our fingertips. Science 2011;333:776-8.

10 Lewis K, Herndon B. Transactive memory systems: current issues and future research directions. Organ Sci 2011;22:1254-65.

11 Huang C. Internet use and psychological well-being: a meta-analysis. Cyberpsychol Behav Soc Netw 2010;13:241-9.

12 Mills KL. Effects of internet use on the adolescent brain: despite popular claims, experimental evidence remains scarce. Trends Cogn Sci 2014;18:385-7.

13 Saunders TJ, Chaput JP, Tremblay MS. Sedentary behaviour as an emerging risk factor for cardiometabolic diseases in children and youth. Can J Diabetes 2014;38:53-61.

14 Weis R, Cerankosky BC. Effects of video-game ownership on young boys' academic and behavioral functioning: a randomized, controlled study. Psychol Sci 2010;21:463-70.

15 Byron T. Safer children in a digital world. Department for Children, Schools and Families, 2008

Cite this as: BMJ 2015;351:h3064

๑) BMJ Publishing Group Ltd 2015 